\title{
Late presentation of intraperitoneal rupture of the urinary bladder
}

\author{
N. S. Williams \\ F.R.C.S.
}

St Andrew's Hospital, Bow, London E3

\begin{abstract}
Summary
A case of silent intraperitoneal rupture of the bladder is presented. The extreme biochemical abnormalities which may occur in this rare condition are well illustrated in this case.
\end{abstract}

\section{Introduction}

RUPTURE of the bladder may be spontaneous or traumatic. It may be intra- or extra-peritoneal. In Bacon's (1943) series of 147 cases, $61.2 \%$ were extra-peritoneal and $38.8 \%$ were intraperitoneal and 102 cases of this series were due to trauma. The predominating symptoms of ruptured bladder are pain, shock, haematuria and retention of urine, the pain and shock being more predominant in the intraperitoneal group. These symptoms and signs are by no means always present. Indeed in Bacon's series one case is described in which the delay between onset of symptoms and presentation was 8 days. Thompson (1965) describes one case of unrecognized bladder rupture which did not present for 2 weeks. Another case of silent rupture is described here.

\section{Case report}

One week before admission, a 58-year-old woman tripped and fell on her abdomen. She considered this to be trivial and did not suffer any immediate symptoms. Several hours later she developed mild, aching suprapubic pain, which she put down to indigestion. She denied any history of alcohol. Throughout the next week she noticed gradual distension of her abdomen and began to vomit two or three times a day. She noticed also that she had not passed as much urine as she thought she should, but apart from this there were no other urinary tract symptoms.

There was no relevant past history.

Examination revealed her to be dehydrated; temperature $99^{\circ} \mathrm{F}$; pulse $100 / \mathrm{min}$; abdomen grossly distended with generalized tenderness, but no guarding; bowel sounds present and normal.

Correspondence: $\mathrm{Mr}$ N. S. Williams, Queen Elizabeth Hospital for Children, Hackney, London, E.8.

\section{Investigations}

Serum sodium, $170 \mathrm{mEq} / \mathrm{l}$; serum potassium, $7 \cdot 0 \frac{\mathrm{\sigma}}{\mathrm{\sigma}}$ $\mathrm{mEq} / \mathrm{l}$; alkali reserve, $10.8 \mathrm{mEq} / \mathrm{l}$; blood urea $196 \frac{0}{3}$ $\mathrm{mg} / 100 \mathrm{ml}$; serum amylase 300 Somogyi units; $;$. straight abdominal X-ray revealed distended loops? of small intestine with free peritoneal fluid.

\section{Progress and treatment}

Nasogastric suction and intravenous infusion were을 established. However, later the same evening she developed severe epigastric pain radiating through to $\frac{7}{0}$ the back. There was now rebound tenderness in the epigastric region and absent bowel sounds. Cathe- $\overrightarrow{0}$ terization revealed $200 \mathrm{ml}$ of normal-looking urine. హे

Laparotomy revealed 81 of urine in the abdominal $\square$ cavity. There was a large circular hole 2 in. diameter straddling the dome of the bladder, so that the interior of the bladder was in continuity with the peritoneal cavity. All urine was removed, and a $\frac{\odot}{\varnothing}$ biopsy taken. Peritoneal toilet was with Noxyflex. $\stackrel{\varrho}{\rightleftarrows}$ The perforation was sutured with chromic catgut in $\frac{\overrightarrow{3}}{3}$ two layers and a Foley's catheter was left in situ.

Cystoscopy on the twelfth post-operative day showed where the perforation had been sutured, but no other abnormality.

Biopsy showed evidence of chronic inflammation compatible with trauma. There was no evidence of 3 . malignancy. The patient made an uneventful 8 recovery and was discharged home on the eighteenth post-operative day, passing urine normally.

\section{Discussion}

Intra-peritoneal rupture of the bladder due to $N$ blunt abdominal trauma is well described (Cosbie Ross, 1943). The majority of cases present very soon 0 after injury with symptoms and signs of peritonism. $\mathbb{\omega}$ The injuries are usually major, although minor $\overline{2}$ injury to a full bladder in the inebriated is a well $\varrho$ described phenomenon.

Several cases are described in which delayed $\stackrel{\oplus}{+}$ clinical manifestations occurred (Goutier Benoit, 뭉 1968; Thompson, 1965; Bastable, de Jode and $\frac{\vec{\Phi}}{\mathbb{D}}$ Warren, 1964).

Thompson stresses the importance of electrolyte $\stackrel{\mathbb{D}}{\stackrel{Q}{Q}}$ 
imbalance due to peritoneal irritation which leads to sequestration of fluid, electrolyte and colloid in the adynamic, distended intestine, leading eventually to severe acidosis. The present case is a good example of this electrolyte imbalance, i.e. hyperkalaemia, hypernatraemia, uraemia and acidosis.

This bizarre biochemical picture is a helpful pointer to the diagnosis when an emergency retrograde cystogram cannot be performed or when the clinical picture is not entirely clear, as was the case in the above patient.

\section{Acknowledgments}

I wish to thank Mr A. J. Walton, under whose care the patient was admitted, for his help and encouragement.

\section{References}

BACON, S.K. (1943) Rupture of the urinary bladder. Clinical analysis of 147 cases in the past ten years. Journal of Urology, 40, 432.

Bastable, J.R.G., DE Jode, L.R. \& W ARRen, P. (1964) Spontaneous rupture of the bladder. British Journal of Urology, 31, 78.

Cosbie Ross, J. (1943) Injuries of the urinary bladder. British Journal of Surgery, 32, 44.

Goutier BENIOT, C. (1968) Traumatic intraperitoneal rupture of the bladder with delayed clinical manifestations. Annales de Chirurgie, 22, 1057.

Thompson, I.M. (1965) Bladder rupture. American Archives of Surgery, 90, 371.

\title{
A case of fat embolism following Shiers' arthroplasty
}

\author{
C. H. BRowne \\ M.B., M.R.C.P. \\ Whipps Cross Hospital, London E11
}

\begin{abstract}
Summary
A case of fatal fat embolism following Shiers' replacement arthroplasty of the knee is reported and some of the mechanisms involved discussed.
\end{abstract}

\section{Introduction}

FAT embolism is a recognized complication of Thompson's replacement arthroplasty of the hip using methylmethacrylate cement (Burgess, 1970; Gresham, Kuczynski and Rosborough, 1971; Sevitt, 1972) but has only rarely been reported in association with total knee replacement (Hume Adams et al., 1972; Blum et al., 1974). In a series of 178 Shiers' arthroplasties, Arden (1973) reported three cases of fat embolism. In this case, as in that reported by Harris (1970), hypotension coincided with release of the tourniquet. Fat embolism as a complication of replacement arthroplasty is distinct from the circulatory effects of methylmethacrylate cement.

\section{Case report}

A 65-year-old woman who had suffered from rheumatoid arthritis for 16 years and been chair-

Address for reprints: Cardiothoracic Institute, Brompton Hospital, London, S.W.3. bound for 3 years, was admitted to hospital for an arthroplasty of the right knee. Her pre-operative condition was good, pulse $76 / \mathrm{min}$, regular; blood pressure $140 / 80 \mathrm{mmHg}$; there was no evidence of cardiac failure.

After routine premedication, a Shiers' arthroplasty using methylmethacrylate bone cement to secure the prosthesis, was carried out. Vent holes were not made. A tourniquet was applied for the duration of the operation, which lasted $65 \mathrm{~min}$. On releasing the tourniquet, her blood pressure, which had been well maintained, fell suddenly to $90 \mathrm{mmHg}$ systolic. Her blood pressure was restored to $135 / 90$ $\mathrm{mmHg}$ by infusing $500 \mathrm{ml}$ of dextrose $4 \%$ saline $0 \cdot 18 \%$ solution.

Following reversal of the anaesthetic, she was breathing normally but was unconscious and unresponsive to all painful stimuli. Crepitations and rhonchi were heard throughout both lung fields.

A provisional diagnosis of fat embolism syndrome was made, which was supported by the chest radiograph, which showed widespread patchy shadowing, and the initial blood gas analysis, which showed a $P_{C O}$ of $30 \mathrm{mmHg}$ and a $P O_{2}$ of $47 \mathrm{mmHg}$. The diagnosis was confirmed over the subsequent $48 \mathrm{hr}$ by the appearance of a petechial rash over the trunk 